\title{
Perfil dos Discentes Ingressos do Centro de Ciências da Saúde UFPE
}

\section{Profile of Enrolled Students at the Center for Health Sciences at UFPE}

\author{
Ludmila Galindo França Gurgel \\ Renata Pedrosa Guimarães \\ Lúcia Carneiro de Souza Beatrice ${ }^{I}$ \\ Cláudio Heliomar Vicente da Silval
}

PALAVRAS-CHAVE:

- Saúde;

- Estudantes;

- Educação Médica;

- Atenção Primária em Saúde.

\section{KEYWORDS:}

- Health;

- Students;

- Medical Education;

- Primary Health Care.

Recebido em: 23/07/2011

Encaminhado em: 24/11/2011

Aprovado em: 28/03/2012

REVISTA BRASILEIRA DE EDUCAÇ̃̃o MÉDICA

\section{RESUMO}

A busca pelo conhecimento das características e da opinião dos estudantes do nível superior fornece importantes subsídios para o planejamento e reorganização do desenvolvimento acadêmico. Com o objetivo de traçar o perfil do aluno do Centro de Ciências da Saúde da Universidade Federal de Pernambuco (UFPE), foram distribuídos formulários aos acadêmicos do $2^{\circ}$ período, contendo perguntas referentes aos seus aspectos socioeconômicos e pessoais. O perfil dos estudantes $(n=210)$ caracterizou-se por um predomínio feminino, com idades entre 19 e 21 anos, provenientes de escolas privadas e classes sociais economicamente mais favorecidas, que receberam grande influência do núcleo familiar na escolha da profissão. A maioria dos estudantes não estava matriculada nos cursos de primeira opção, porém possuía alta expectativa com relação ao curso, considerando-o correspondente às suas expectativas. Após formados pretendem realizar algum curso de pós-graduação e trabalhar no serviço público. No entanto, persiste um problema relativo à escolha da profissão, regulada pela condição socioeconômica e influência familiar.

\section{ABSTRACT}

Carrying out surveys that attempt to understand the characteristics and opinions of students at university level may provide important information for planning and reorganizing academic development. In order to profile the students of the Center for Health Sciences, at the Federal University of Pernambuco, questionnaires were distributed to the academics in the second term of the course, containing questions regarding their socio-economic and personal aspects. The profile of students $(n=$ 210) was characterized by a predominance of females, aged between 19 and 21 years, who had been to private schools, were from the most economically advantaged social classes, and had been greatly influenced by their family regarding career choice. Most students were not enrolled in the courses they had chosen as their first option, but had high expectations about the course, and considered that the course met their expectations. After finishing the course, most students intend to take a postgraduate course and work in public service. One problem that remains concerning the choice of the profession, is that it might be determined by socio-economic status and family influence. 


\section{INTRODUÇÃO}

Os processos educativos buscam a passagem do estado de desconhecimento relativo para um estado de conhecimento capaz de transformar a realidade ${ }^{1}$.

A educação, enquanto processo social, extrapola o formal, aqui considerado como escolar em todos os níveis, pois necessita de sistematização para instrumentalizar indivíduos capazes de gerar e realizar as mudanças desejadas. $\mathrm{O}$ ensino superior está inserido em um momento educacional brasileiro em que as oportunidades para a construção do conhecimento devem somar-se à consciência crítica do aluno, considerando também o aprendizado adquirido e construído no contexto do indivíduo, no meio em que ele vive, na pesquisa e/ou extensão para a aprendizagem ${ }^{1,2}$.

Para que o ensino se constitua prática vinculada aos interesses maiores da sociedade, é necessária uma redefinição dos projetos pedagógicos dos cursos de graduação. O processo de mudança da educação traz inúmeros desafios, dentre os quais: a ruptura com estruturas cristalizadas (a fragmentação curricular), com modelos de ensino tradicional (estratégias de ensino que estimulam a passividade discente), com a pouca integração ensino-serviços-comunidade; e a consolidação da formação de profissionais da saúde com competências que lhes permitam recuperar a dimensão essencial do cuidado a relação entre humanos ${ }^{3,4}$.

Nesse contexto, o aluno não pode ser reduzido a objeto do ensino, mas, assim como o docente, é também agente da sua própria formação ${ }^{5}$. Professor e aluno representam papel fundamental nesse sentido, visto serem responsáveis diretos por essas mudanças ${ }^{4}$.

Com o que se pretende, o papel desempenhado pelo professor é preponderante para o desenvolvimento do aluno; ou seja, é necessário que o professor trabalhe, por meio de seus recursos metodológicos, com a motivação extrínseca, criando situações para que o aluno também possa se desenvolver a partir do seu processo de formação ${ }^{4}$. Consequentemente, as propostas de transformação do ensino, para alcançar profundidade, devem dar atenção aos preconceitos e às aspirações do estudante, à bagagem de que ele é portador.

Portanto, faz-se necessário considerar que os estudantes são indivíduos muito diferentes uns dos outros e sujeitos a mudanças com base em diferentes experiências de vida, conhecimentos adquiridos e expectativas sobre o que e como aprender. Certamente, nem todos aprendem da mesma maneira, com a mesma prontidão ou com o mesmo significado em cada material e situação de ensino. No entanto, é possível apropriar-se do estado atual do conhecimento sobre aprendi- zagem e traçar um plano de investigação sobre os próprios alunos - os conhecimentos e as habilidades considerados importantes e adequados a seu nível de estudo — bem como sobre as estratégias, os recursos ${ }^{6}$ e as impressões sobre suas escolhas dentro do ensino. Sendo assim, a construção de uma concepção acerca do sujeito perpassa pelo entendimento deste com seu primeiro núcleo de socialização, a família ${ }^{7}$.

Os dados da literatura apontam que o perfil da demanda para a área biológica, em todos os nove cursos, é caracterizado por uma porcentagem de candidatos do sexo feminino que ultrapassa $50 \%$, sendo em seis delas maior que $58 \%$. Há uma concentração dos candidatos de alto poder aquisitivo em cursos de elevado prestígio social, para os quais só conseguirão ser selecionados os que obtiverem excelente rendimento nas provas. Isso justifica a preferência dos concorrentes da classe média baixa por cursos de baixo prestígio social, nos quais pode obter-se a vaga com desempenho mediano ${ }^{8}$. Segundo Tragtenberg et al. ${ }^{9}$, o percentual de alunos negros matriculados nos cursos da saúde variou 2,2\% para odontologia, 4,7\% para medicina, cursos considerados de maior prestígio social, e 5,1\% para educação física, curso considerado de menor prestígio social, sendo a raça autodeclarada.

Ações direcionadas, que possibilitem a motivação extrínseca dos estudantes da saúde, exigem o conhecimento do perfil dos que ingressam na Universidade, suas expectativas em relação ao curso e perspectivas após a graduação. O objetivo deste estudo foi caracterizar o perfil dos estudantes que ingressam nos cursos do CCS/UFPE.

\section{METODOLOGIA}

Esta pesquisa teve aprovação no Comitê de Ética e Pesquisa do Centro de Ciências da Saúde (CCS) da Universidade Federal de Pernambuco (UFPE) (236/2009).

Foi realizado um estudo observacional transversal, tendo como alvo amostral o universo de estudantes dos cursos de medicina, enfermagem, odontologia, fisioterapia, terapia ocupacional, nutrição, fonoaudiologia, educação física e farmácia do CCS/UFPE regularmente matriculados no $2^{\circ}$ semestre letivo do ano de 2010 - fase inicial de aprendizado do curso com atividades teóricas e laboratoriais -, o que permitiu registrar a primeira impressão sobre o curso. A seleção da amostra (n = 210) se deu pelo cálculo proporcional ao número de alunos cuja entrada no ensino superior era referente ao ano de 2010 (Tabela 1); e os participantes tiveram seus nomes sorteados aleatoriamente. Foram excluídos aqueles que cursavam as disciplinas correspondentes ao $2^{\underline{o}}$ semestre letivo, mas haviam iniciado o curso em outro período. 
TABELA 1

Relação de vagas ofertadas e amostras selecionadas para cada curso do CCS/UFPE

\begin{tabular}{lccc}
\hline Curso & $\begin{array}{c}\text { No de } \\
\text { vagas }\end{array}$ & $\begin{array}{c}\text { Amostra } \\
\text { Proporcional }\end{array}$ & $\begin{array}{c}\text { Amostra } \\
\text { Final }\end{array}$ \\
\hline Enfermagem & 40 & 17 & 20 \\
Medicina & 70 & 29 & 28 \\
Odontologia & 120 & 58 & 60 \\
Fisioterapia & 33 & 14 & 15 \\
Fonaudiologia & 30 & 13 & 19 \\
Nutrição & 30 & 13 & 11 \\
Terapia Ocupacional & 18 & 8 & 6 \\
Farmácia & 45 & 18 & 22 \\
Educação Física & 60 & 25 & 210 \\
\hline Total & 376 & 195 & \\
\hline
\end{tabular}

Após leitura e assinatura do termo de Consentimento Livre e Esclarecido, os participantes responderam a um formulário anônimo com respostas de múltipla escolha e descritivas sobre aspectos socioeconômicos, demográficos, conhecimento, perspectivas sobre o curso que escolheram e o mercado de trabalho (Figura 1).

FigURA 1

Diagrama representativo dos fatores que interferem no perfil dos estudantes do CCS/UFPE.

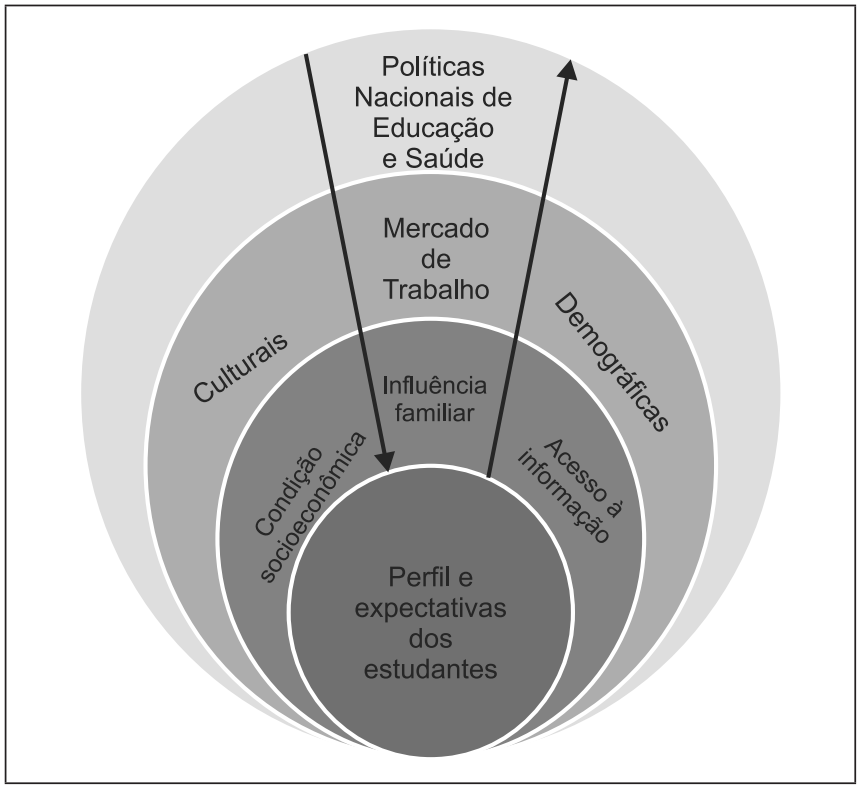

Os dados coletados foram tabulados e submetidos a técnicas de estatística descritiva, por meio de distribuições absolutas, percentuais, e técnicas de estatística inferencial, a partir do qui-quadrado de Pearson ou o teste exato de Fisher, com nível de significância de $5 \%$, através do programa de análise estatística SPSS (Statistical Package for the Social Sciences) na versão 13.

\section{RESULTADOS}

Da amostra, $71 \%$ eram do gênero feminino $(n=149)$, com predominância dele em todos os cursos, sendo a totalidade dos entrevistados de enfermagem. A faixa etária de maior concentração de estudantes situa-se entre 19 e 21 anos. Os cursos que apresentaram os estudantes mais jovens (até 18 anos) foram: fonoaudiologia, farmácia, educação física e fisioterapia; e, em oposição, um maior número de estudantes acima de 22 anos foram encontrados em: educação física, terapia ocupacional, fonoaudiologia e medicina, respectivamente (Tabela 2).

TABELA 2

Avaliação do curso segundo a faixa etária

\begin{tabular}{|c|c|c|c|c|c|c|c|c|c|}
\hline \multirow{2}{*}{$\begin{array}{c}\text { Faixa etária/ } \\
\text { Curso }\end{array}$} & \multicolumn{2}{|c|}{ Até 18} & \multicolumn{2}{|c|}{19 a 21} & \multicolumn{2}{|c|}{22 ou mais } & \multicolumn{2}{|c|}{ Total } & \multirow{3}{*}{$\begin{array}{l}\text { Valor } \\
\text { de p }\end{array}$} \\
\hline & $\mathbf{n}$ & $\%$ & $\mathbf{n}$ & $\%$ & $\mathbf{n}$ & $\%$ & $\mathrm{n}$ & $\%$ & \\
\hline Grupo Total & 43 & 20,5 & 121 & 57,6 & 46 & 21,9 & 210 & 100,0 & \\
\hline Odontologia & 9 & 15,0 & 41 & 68,3 & 10 & 16,7 & 60 & 100,0 & $\mathrm{p}^{(1)}=0,251$ \\
\hline Educação Física & 6 & 20,7 & 11 & 37,9 & 12 & 41,4 & 29 & 100,0 & \\
\hline Medicina & 4 & 14,3 & 18 & 64,3 & 6 & 21,4 & 28 & 100,0 & \\
\hline Farmácia & 8 & 36,4 & 10 & 45,5 & 4 & 18,2 & 22 & 100,0 & \\
\hline Enfermagem & 3 & 15,0 & 14 & 70,0 & 3 & 15,0 & 20 & 100,0 & \\
\hline Fonoaudiologia & 7 & 36,8 & 7 & 36,8 & 5 & 26,3 & 19 & 100,0 & \\
\hline Fisioterapia & 3 & 20,0 & 10 & 66,7 & 2 & 13,3 & 15 & 100,0 & \\
\hline Nutrição & 2 & 18,2 & 7 & 63,6 & 2 & 18,2 & 11 & 100,0 & \\
\hline Terapia & & & & & & & & & \\
\hline Ocupacional & 1 & 16,7 & 3 & 50,0 & 2 & 33,3 & 6 & 100,0 & \\
\hline
\end{tabular}

Nota: (1) Através do teste de Verossimilhança.

A maioria dos estudantes que ingressaram na Universidade na faixa etária entre 19 e 21 anos frequentaram cursinho de matérias isoladas. Cinquenta e três por cento cursaram o ensino médio em instituições particulares.

Sessenta e nove por cento dos estudantes da saúde situaram-se, na classificação econômica, nas classes A (16,2\%) e B $(52,9 \%)$. Os estudantes de medicina estavam concentrados, em quase sua totalidade $(96,4 \%)$, nas classes A $(50 \%)$ e B $(46,4 \%)$. Nos demais cursos, prevaleceu a maior concentração na classe B, com exceção da Educação Física $(55,2 \%)$ e Fonoaudiologia $(52,6 \%)$, cujos estudantes concentravam-se na classe C. Apenas uma parcela muito pequena dos estudantes $(2,9 \%)$ pertencia à classe D, incluindo os cinco cursos (medicina, enfermagem, farmácia, fisioterapia e terapia ocupacional), que não apresentaram nenhum representante desse estrato social (Gráfico 1).

A maioria dos entrevistados pretende residir com toda a família $(86,2 \%)$ durante o curso. 
GRÁFICO 1

Distribuição da classificação econômica segundo o curso.

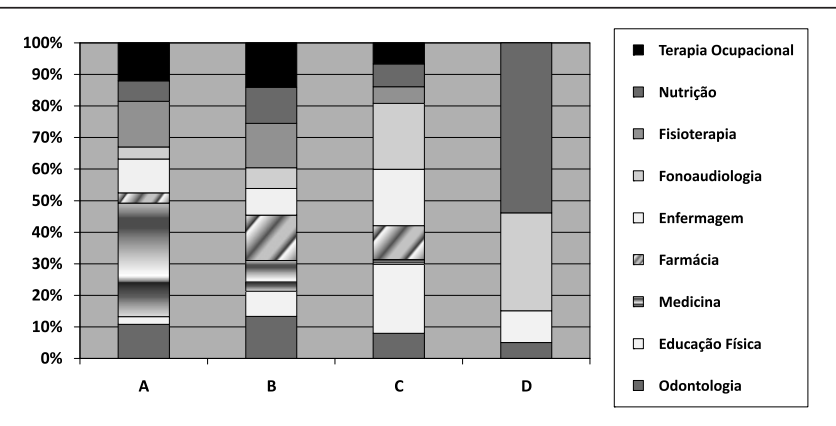

Quando questionados se o curso em que estavam matriculados era a sua primeira opção, 56,7\% dos estudantes afirmaram que sim, sendo os cursos de medicina, educação física, odontologia, nutrição e farmácia os que mostraram uma prevalência acima de $50 \%$, com destaque para medicina, em que $89,3 \%$ estavam matriculados no curso de primeira opção.

A maioria dos estudantes $(66,2 \%)$ não possuía ninguém da família que exercesse a mesma profissão, os que possuíam estavam concentrados nas classes sociais A e B. Houve relatos de altas expectativas com relação aos cursos em que estavam matriculados. Apenas no curso de terapia ocupacional os estudantes tiveram expectativas qualificadas em média/baixa com maior frequência $(66,7 \%)$.

Um pouco mais da metade dos estudantes (54,3\%) tinha conhecimento sobre o projeto pedagógico do curso. Os que afirmaram desconhecê-lo, em sua maioria, eram dos cursos de terapia ocupacional, nutrição, fisioterapia, enfermagem e educação física (Tabela 3).

TABEla 3

Avaliação do conhecimento sobre o projeto pedagógico do curso

\begin{tabular}{|c|c|c|c|c|c|c|c|}
\hline \multirow{2}{*}{ Curso } & \multicolumn{2}{|c|}{ Sim } & \multicolumn{2}{|c|}{ Não } & \multicolumn{2}{|c|}{ TOTAL } & \multirow{2}{*}{ Valor de $\mathrm{p}$} \\
\hline & $\mathrm{n}$ & $\%$ & $\mathbf{n}$ & $\%$ & $\mathrm{n}$ & $\%$ & \\
\hline Grupo Total & 114 & 54,3 & 96 & 45,7 & 210 & 100,0 & \\
\hline Odontologia & 43 & 71,7 & 17 & 28,3 & 60 & 100,0 & $\mathrm{p}(1)=0,004^{*}$ \\
\hline Educação Física & 14 & 48,3 & 15 & 51,7 & 29 & 100,0 & \\
\hline Medicina & 19 & 67,9 & 9 & 32,1 & 28 & 100,0 & \\
\hline Farmácia & 12 & 54,5 & 10 & 45,5 & 22 & 100,0 & \\
\hline Enfermagem & 8 & 40,0 & 12 & 60,0 & 20 & 100,0 & \\
\hline Fonoaudiologia & 10 & 52,6 & 9 & 47,4 & 19 & 100,0 & \\
\hline Fisioterapia & 4 & 26,7 & 11 & 73,3 & 15 & 100,0 & \\
\hline Nutrição & 3 & 27,3 & 8 & 72,7 & 11 & 100,0 & \\
\hline Terapia Ocupacional & 1 & 16,7 & 5 & 83,3 & 6 & 100,0 & \\
\hline
\end{tabular}

Nota 1: (*) Diferença significativa ao nível de 5,0\%.

Nota 2: (1) Através do teste Qui-quadrado de Pearson.
Segundo a avaliação dos estudantes, os conteúdos ministrados pelos professores nas disciplinas, até o momento da pesquisa, estavam dentro das expectativas $(62,9 \%)$, com uma perspectiva de aproveitamento desses conteúdos no exercício da profissão qualificado acima de $50 \%$ para $81,9 \%$ dos estudantes.

Em relação ao setor (público/privado/autônomo) onde pretenderiam trabalhar após a graduação, 57,1\% visaram ao serviço público, sobretudo para os cursos de fonoaudiologia, enfermagem e farmácia. Vinte três por cento ainda não sabiam em qual setor iriam trabalhar.

A remuneração almejada com o exercício da profissão concentrou-se nas faixas entre 6 a 10 e entre 11 a 20 salários mínimos. Os estudantes de medicina, odontologia e terapia ocupacional são os que almejaram as remunerações mais altas, acima de 20 salários. Vale destacar que tal fato se deu principalmente entre os estudantes de medicina, os quais optaram igualmente entre as duas maiores faixas de remuneração.

Quando questionados se pensaram em trancar o curso, 30 $(14,3 \%)$ responderam afirmativamente. O motivo mais citado foi a dúvida sobre a escolha $(n=12)$ adequada do curso. Um número maior, 90 participantes, afirmaram ter pensado em algum momento em fazer outro curso, mas não o fizeram porque "gostavam do curso escolhido" ( $=12)$ ou "preferiram o curso escolhido" ( $\mathrm{n}=13)$. Outros afirmaram que a escolha do curso em que estão matriculados se deu por considerarem a outra opção com "maior dificuldade de ingresso" (n = 9) ou "não conseguiram passar" ( $n=3)$ para outro curso.

\section{DISCUSSÃO}

Desde 1985, Machado ${ }^{10}$ já afirmava que a participação das mulheres no mercado de trabalho da saúde é majoritária e crescente, alcançando cerca de $70 \%$ do total. Segundo o autor $^{10}$, algumas categorias de profissionais da saúde têm longa tradição de serem tipicamente femininas, como os enfermeiros e o pessoal auxiliar da área de enfermagem. Em outros grupos, há uma predominância de fisioterapeutas, por exemplo. Finalmente, há categorias que vem apresentando um acelerado processo de feminilização, é o caso dos médicos e dos odontólogos. O perfil dos estudantes do CCS/UFPE é predominantemente do gênero feminino (71\%), o curso de enfermagem se destacou por ter $100 \%$ dos questionados mulheres, tendência já vista em outros estudos ${ }^{11,12,13,14}$. O estudo de Ferreira et al. $^{5}$ chama a atenção para o fato de praticamente $50 \%$ do quadro estudantil de medicina estar constituído por mulheres. A tendência crescente da participação feminina na medicina vem há algumas décadas ocorrendo em diversos países. 
A justificativa para essa maior prevalência feminina deve-se ao fato de elas acreditarem que poderão conciliar, eficazmente, suas vidas pessoais e profissionais como cirurgiãs-dentistas $^{15}$. Na literatura, a escolha da odontologia como uma carreira profissional era focada nas horas regulares de trabalho, na segurança financeira, no desejo de trabalhar com as pessoas, trabalhar com as próprias mãos e de ter uma profissão sem vínculo empregatício ${ }^{14}$, no ganho financeiro, no prestígio da profissão e na percepção entre as mulheres de que podem servir à comunidade $\mathrm{e}^{16,17}$.

A maioria era constituída por jovens na faixa etária menor ou igual a 21 anos (78\%) e somente 35,2\% tiveram aprovação no primeiro vestibular. No estudo de Ferreira et al. ${ }^{5}$ houve uma aprovação de 50\% dos estudantes de medicina na primeira tentativa.

Apesar dos esforços governamentais para facilitar o acesso da população menos favorecida às Instituições de Ensino Superior (IES) brasileiras por meio de ações apoiadas em três importantes pilares: 1) a expansão das universidades federais pelo Reuni; 2) o Programa Universidade para Todos (Prouni); e 3) a Universidade Aberta do Brasil (UAB), além do sistema de cotas (raciais e de escolas públicas), os estudantes das IES federais, aqui representados por aqueles da área da saúde, ainda são de classes sociais economicamente mais favorecidas, principalmente da classe B $(n=111)$. Tal fato corrobora com os resultados apontados pela literatura, que mostraram uma renda familiar dos estudantes de medicina situada entre $10 \mathrm{e}$ 50 salários mínimos em $2 / 3$ dos casos compatíveis com a origem de classe média alta, embora em aproximadamente $12 \%$ a renda familiar seja inferior a 10 salários $^{5}$.

Silva et al. ${ }^{18}$ encontraram uma maioria dos estudantes de odontologia das Universidades públicas brasileiras provenientes de escolas privadas e de famílias das classes média e alta. De forma contraditória, em uma Universidade privada de enfermagem havia um maior número de pessoas que tinham sua formação no nível médio em escola pública $(56 \%)^{11}$. Além das grandes diferenças entre ricos e pobres no que se refere ao nível de escolaridade, também é bastante claro para a sociedade que a inserção dos alunos nas escolas não garante que todos recebam a mesma qualidade de ensino. A qualidade da educação adquirida por cada indivíduo é influenciada por diversos fatores, sejam eles de ordem familiar, particularmente o nível de renda da família e a escolaridade dos pais, sejam devidos a fatores relacionados à baixa qualidade da educação oferecida pela escola que frequenta ${ }^{19}$. No Brasil, isso se explica pela notável superioridade da qualidade das escolas de ensino médio privadas. As escolas públicas têm não só baixo nível socioeconômico como também baixa dispersão. As escolas particulares têm, em contrapartida, alta variação. Isso indica que seus alunos têm posição social em uma ampla faixa de variação ${ }^{20}$. Dada a relação entre educação e renda, conclui-se que as diferenças na qualidade da educação básica tendem a se transformar, futuramente, em disparidades de rendimentos ${ }^{19}$.

A forma como obtiveram as informações sobre a profissão reflete igualmente a forte influência do núcleo familiar, 41,9\% dos estudantes consideraram os familiares como responsáveis pelo acesso a tais informações. Portanto, a construção de uma concepção acerca do sujeito da educação perpassa pelo entendimento da relação deste com seu primeiro núcleo de socialização - a família. O longo processo de subjetivação do homem se inicia na família. A subjetividade é uma construção cultural que muda com o tempo. Sendo assim, o homem do século XXI não é o mesmo da Idade Média. A família de hoje retrata um novo filho e, em consequência disso, surge outro perfil de aluno. O século XXI marca a entrada num novo mundo, em que professor e aluno desempenham papéis cada vez mais complexos, formando um ambiente com duas gerações em diálogo. Não obstante, a conquista da autonomia do sujeito na educação não é uma tarefa fácil. O desenvolvimento da subjetividade está relacionado com a qualidade do ensino, isso quer dizer que a autonomia do aluno depende de um movimento de reforma educacional que vislumbre a formação humanística do cidadão ${ }^{7}$.

A escolha de uma profissão é motivo de dúvidas e questionamentos entre os estudantes, pois essa decisão é tomada, muitas vezes, de forma imatura e associada à falta de conhecimento sobre a carreira escolhida e às demandas sociodemográficas. Um número expressivo dos estudantes (43,3\%) do CCS/UFPE não está matriculado no curso de primeira opção. O estudo de Lalloo, Ayo-Yusuf, Yengopal ${ }^{21}$ mostrou que, para $1 / 3$ dos participantes, a odontologia não foi a primeira escolha. Essa tendência mostrou-se ainda mais forte nos cursos do CCS/UFPE relacionados neste estudo. Não só no curso de odontologia, em que 41,7\% dos seus estudantes não cursavam o curso de primeira opção, mas nos demais cursos do CCS/ UFPE foi observado esse fato. Na fonoaudiologia, 63,2\% (19) dos estudantes não estavam matriculados no curso de primeira opção, dado que foi contrário ao observado por Chun, Bahia $^{22}$, em que, dos 24 sujeitos participantes da pesquisa, 13 alunos (54\%) escolheram o curso de fonoaudiologia como primeira opção no vestibular, e 11 (46\%) apresentaram outras opções de curso. Excetuando-se o curso médico, que foi referido como primeira opção em $89,3 \%$ dos casos, e o de educação física $(62,1 \%)$, o curso de terapia ocupacional $(83,3 \%)$ teve a maior porcentagem de incompatibilidade entre o curso de primeira opção e o curso em andamento. A escolha pode ser feita 
por motivos inapropriados, acarretando na descoberta tardia dos estudantes de que essa profissão não supre às suas necessidades psicossociais, levando ao abandono da carreira após o término do curso. Quando essa descoberta ocorre durante o curso, pode ocorrer a desistência de concluí-lo ou, de forma mais grave, a formação de um profissional desestimulado ${ }^{14}$.

O desconhecimento do projeto pedagógico pode contribuir para o desapontamento e o desestímulo em relação ao curso ou, mais tardiamente, em relação à profissão. Um alto percentual de estudantes $(45,7 \%)$ relatou desconhecer os projetos pedagógicos dos respectivos cursos. Os maiores índices de conhecimento do projeto pedagógico do curso foram em medicina e odontologia, cursos que abordam o projeto no primeiro semestre em virtude da reformulação curricular. É imperioso lembrar que, além do desconhecimento da profissão, alguns preconceitos sociais a respeito das profissões podem gerar um estereótipo equivocado em relação a elas. Isso foi revelado no estudo de Jesus et al. $^{23}$ por meio da percepção de enfermeiros formados em diferentes décadas. Uma parte significativa dos colaboradores da pesquisa (26\%) mencionou que não foi apoiada pelas suas famílias quando optaram pela enfermagem. Os discursos revelaram que os colaboradores perceberam atitudes preconceituosas por parte de pessoas próximas no momento da escolha profissional. A opção pela profissão, na maioria dos casos, é sempre secundária e hierarquicamente inferior à profissão médica.

Com relação às perspectivas futuras para o exercício da profissão, há um maior interesse dos estudantes que ingressam nos cursos pelo serviço público, $57,1 \%$ pretendem trabalhar nesse seguimento de mercado ao término do curso. Erdmann et al. ${ }^{24}$ constataram em seu estudo que mais da metade dos estudantes pretendem trabalhar no serviço público de saúde, com exceção dos representantes do curso de nutrição e grande parte dos de odontologia. Prevalece, nos cursos de enfermagem e medicina, o maior número de pessoas interessadas em seguir carreira na saúde pública. No entanto, neste estudo, foi observada exceção entre os representantes do curso de nutrição e grande parte dos de medicina. Os cursos em que prevaleceu o maior número de interessados na carreira da saúde pública foram: fonoaudiologia e enfermagem. Nesse contexto, surpreendentemente, situa-se a fonoaudiologia, cuja formação apresenta um incipiente contato com a Saúde Coletiva e com os movimentos de construção de lutas que reafirmam uma política pública de saúde no Brasil, o que favorece a reprodução do modelo tradicional médico-centrado e pautado no atendimento à demanda espontânea e terapêutica reabilitadoras.

Isso provavelmente se justifica pela aspiração de um emprego seguro, mais comumente público, como um fator impor- tante, como encontrado por Laloo, Ayo-Yusuf, Yengopal ${ }^{21}$, em estudo realizado na África do Sul, país com instabilidade econômica, semelhante ao Brasil nesse aspecto, que provoca insegurança no setor privado e na carreira autônoma e gera uma maior demanda de profissionais para o setor público. Ceccim et al. ${ }^{25}$ evidenciaram a vigência de um imaginário de atuação liberal-privatista conjugado ao trabalho no segmento público-estatal, no qual se obteria maior experiência com doenças e diversidades do sofrimento. O lugar ideal de trabalho seria o privado, de livre arbítrio dos profissionais e usuários, mas com vínculo estatal para experiência, oportunidade de estudo e chances de bolsas de pesquisa e estágio no exterior. Apesar da expectativa para com a área privada, inexistem ensino e formação relativos ao conhecimento da saúde suplementar, assim como sobre os sentidos da regulação pelo Sistema Único de Saúde (SUS). O universo da pesquisa compreendeu todos os estudantes formandos dos cursos de medicina, odontologia e psicologia destas universidades e todos os professores que desenvolvem atividades docentes junto a estes estudantes. A opção por essas três carreiras da saúde aconteceu por se tratarem, embora não exclusivamente, de áreas de atuação com forte apelo à autonomia profissional e independência na formulação de diagnósticos e indicações terapêuticas em que mais claramente se manifesta a ideação de profissão liberal. Tais profissões caracterizam-se principalmente pela ênfase no atendimento individual direto ao usuário ${ }^{25}$.

$\mathrm{O}$ fato de os estudantes de medicina e odontologia almejarem remunerações maiores deve-se, provavelmente, à origem desses estudantes provenientes de estratos sociais mais altos. Em medicina, 50\% dos estudantes são da classe social A e $46,4 \%$, da classe B; na odontologia, apesar do percentual na classe mais alta (15\%) ser menor, 63,3\% pertencem à classe B. Adicionalmente, nas classes mais altas, a influência familiar parece ter maior peso na escolha do curso, já que $58,8 \%$ dos estudantes da classe social A, 32,4\% classe social B e $25,4 \%$ classe social C têm familiares que exercem a mesma profissão, mostrando que nos estratos mais altos há forte influência do núcleo familiar na escolha do curso.

A dificuldade e a imaturidade da decisão do curso podem ser vistas por meio das respostas aos questionamentos sobre: "se pensaram em trancar o curso" ou "se pensaram em algum momento fazer outro curso". À primeira questão 30 (14,3\%) responderam afirmativamente, um número maior, 90 (42,9\%) participantes, afirmou ter pensado em algum em momento fazer outro curso, mas não o fizeram porque "gostavam do curso escolhido" (12) ou "preferiram o curso escolhido" (13). Cabe notar que a incompatibilidade entre essas duas respostas demonstra a fragilidade dessa tomada de decisão. Outras 
respostas relacionadas ao tema levam em consideração o fato de a outra opção apresentar "maior dificuldade de ingresso" (9) ou o de que não "conseguiram passar"(3) para o curso pretendido, expondo a nítida escolha com base não pela vocação, mas na maior acessibilidade a determinados cursos em detrimentos de outros.

Diante do quadro exposto, vê-se que são grandes os obstáculos para se adequar às fortes mudanças sofridas pela saúde no Brasil nas décadas de 1980 e 1990, com a criação de um sistema universal, o Sistema Único de Saúde (SUS). Apesar do SUS ser o sistema de saúde vigente, amparado na Constituição Federal desde 1988 e regulamentado pelas Leis Orgânicas de 1990, seus princípios democráticos trabalham diretrizes, conceitos e práticas que eram e ainda são contra-hegemônicos na sociedade, dificultando sua consolidação ${ }^{26}$. O sistema hegemônico traz a atenção à saúde centrada na assistência curativa, hospitalar e superespecializada, na vertente de interesses econômicos e corporativos. A substituição desse sistema pelo sistema universal, que busca modelos de atenção que valorizem a integralidade, o cuidado humanizado e a promoção da saúde depende do perfil de formação e da prática dos profissionais de saúde ${ }^{27}$.

Portanto, é necessário acabar com esse nítido descompasso entre a formação dos novos profissionais da saúde e os princípios e diretrizes do SUS, diante do grande número de estudantes que vislumbram se enquadrar no serviço público ao término do curso.

\section{CONCLUSÕES}

Os cursos do CCS/ UFPE caracterizaram-se por um perfil de estudantes de distribuição homogênea por gênero, idade e classe social. Aqueles cursos que exigem um melhor desempenho para o ingresso foram representados por estudantes de classes sociais e faixa etária mais elevadas. Já as classes sociais menos favorecidas possuíram discreta representatividade nessa amostra. Adicionalmente, a escolha da profissão é motivada, sobretudo, pela maior facilidade de acesso aos cursos e pela influência familiar em detrimento ao fator vocacional.

\section{REFERENNCIAS}

1. Emi Ito E, Peres AM, Takahashi RT, Leite MHJ. O ensino de enfermagem e as Diretrizes Curriculares Nacionais: utopia x realidade. Rev. Esc. Enferm. 2006; 40(4) 570-575.

2. Peres AM. Sistema de informações sobre pesquisa em enfermagem: proposta para um departamento de ensino de universidade pública. Florianópolis; 2002 Mestrado [dissertação] -Centro Socioeconômico da UFSC.p.33.
3. Cyrino EG, Toralles-Pereira Ml. Trabalhando com estratégias de ensino-aprendizagem por descoberta na área da saúde: a problematização e a aprendizagem baseada em problemas. Cad. Saúde Pública 2004; 20(3)780-788.

4. Noro LRA, Albuquerque DF, Ferreira MEM. O desenvolvimento do processo ensino-aprendizagem: visão do aluno e do professor. Rev. da Abeno 2006; 6(2)109-114.

5. Ferreira RA, Peret Filho LA, Goulart EMA, Valadão MMA. O estudante de medicina da Universidade Federal de Minas Gerais: perfil e tendências. Rev. Ass. Med. Brasil 2000; 46(3) 224-231.

6. Luce MB. Prática acadêmica: metodologias e tecnologias de ensino em questão. Educ. Bras. 2001; 23(47)103-108.

7. Souza KSM. O sujeito da educação superior: subjetividade e cultura. Psicologia em Estudo 2009; 14(1)129-135.

8. Braga MM, Peixoto MCL, Bogutchi TF. Tendências da demanda pelo ensino superior: estudo de caso da UFMG. Cad. Pesqui. [on-line]. 2001.113 [capturado em 07 jan. 2011]; 129-152 . Disponível em: http://www. scielo.br / scielo.php?script=sci_arttext\&pid $=$ S0100 $-15742001000200007 \& \operatorname{lng}=p t \& n r m=$ iso.

9. Tragtenberg MHR, Bastos JLD, Nomura LH, Peres MA. Como aumentar a proporção de estudantes negros na universidade? Cad. Pesqui. [on-line]. 2006. 36(28). [capturado em 07 jan. 2011]; 473-495. Disponível em: http:// www.scielo.br/scielo.php?script=sci_arttext\&pid=S0100$-15742006000200010 \& \operatorname{lng}=$ pt\&nrm=iso.

10. Machado MH. A força de trabalho feminino em saúde no Brasil 1970-1980, Belo Horizonte, 1985 (inédito). p.46.

11. Santos CE, Leite MMJ. O perfil do aluno ingressante em uma universidade particular da cidade de São Paulo. Rev. Bras. Enferm. 2006; 59(2):154-156.

12. Silva AFF, Silva CV. Perfil dos estudantes de terapia ocupacional da escola superior de saúde do Alcoitão. Rev. Essa 2006; 3: 37-64

13. Wetterich NC, Melo MRAC. Perfil sociodemográfico do aluno do curso de graduação em enfermagem. Rev. Latino-Am. Enfermagem 2007; 15(3): 404-410.

14. Aguiar CM, Pessoa MAV, Câmara AC, Perrier RA, Figueiredo JAP. Factors involved in the choice of dentistry as an occupation by Pernambuco dental students in Brazil. J. Dent. Educ. 2009; 73(12): 1401-1407.

15. Bedi R, Gilthorpe MS. Ethnic and gender variations in university applicants to United Kingdom medical and dental schools. Br. Dent. J. 2000; 189(4): 212-215.

16. Brand AA, Chikte UM, Thomas CJ. Choosing dentistry as a career - a profile of entering students to the University of Sydney, Australia. Aust. Dent. J. 1996 41(3):198-205. 
17. Coombs JA. Factors associated with career choice among women dental students. J. Dent. Educ. 1976; 40(11): 724732.

18. Silva ET, Nunes MF, Queiroz MG, Leles CR. Factors influencing students' performance in a Brazilian dental school. Braz. Dent. J. 2010; 21(1): 80-86.

19. Ney MG, Totti MEF, Reid TLS. A influência das condições socioeconômicas das famílias na qualidade da educação básica na região Norte Fluminense. Vértices 2010; 12(1): 103-119.

20. Soares JF, Andrade RJ. Nível socioeconômico, qualidade e equidade das escolas de Belo Horizonte. Ensaio: Aval. Pol. Públ. Educ. 2006; 4(50):107-126.

21. Lalloo R, Ayo-Yusuf AO, Yengopal V. Early phase dental students' motivations and expectations concerning the study and profession of dentistry. SADJ 2008; 63(4): 216-20.

22. Chun RYS, Bahia MM. O uso do portfólio na formação em fonoaudiologia sob o eixo da integralidade. Cefac 2009; 11(4): 688-694.

23. Jesus ES, Marques LR, Assis LCF, Alves GFF, Oguisso T. Preconceito na enfermagem: percepção de enfermeiros formados em diferentes décadas. Rev. Esc. Enferm. USP 2009; 44(1): 166-173.

24. Erdmann AL, Rodrigues ACRL, Koerich MS, Backes DS, Drago LC, Klock P. O olhar dos estudantes sobre sua formação profissional para o Sistema Único de Saúde. Acta Paul. Enferm. 2009; 22(3): 288-94.

25. Ceccim RB, Armani TB, Oliveira DLLC, Bilibio LF, Moraes M, Santos ND. Imaginários da formação em saúde no Brasil e os horizontes da regulação em saúde suplementar.
Ciênc. Saúde Coletiva [on-line]. 2008. 13(5) [capturado em 07 jan 2011]; 1567-1578.

26. Merhy EE, Feuerweker LCM, Ceccim RB. Educación permanente en salud - una estrategia para intervenir en la micropolítica del trabajo en salud. Salud Colect 2006; 2(2): 147-160.

27. Almeida MJ, Campos JB, Turini B, Nicoletto SCS, Pereira LA, Rezende LR, Mello PL. A implantação das diretrizes curriculares nacionais na graduação em medicina no Paraná. Rev. Bras. Educ. Med. 2007; 31(2):156-165.

\section{CONTRIBUIÇÃO DOS AUTORES}

Ludimila Galindo F. Gurgel participou na elaboração do projeto, coleta dos dados, redação e revisão do artigo. Renata P. Guimarães participou na elaboração do projeto e revisão do artigo. Lúcia C. de Souza Beatrice co-orientou e revisou na confecção do artigo. Cláudio H. V. da Silva orientou na redação e revisou o artigo.

\section{CONFLITO DE INTERESSES}

Declarou não haver.

\section{ENDEREÇO PARA CORRESPONDÊNCIA}

Cláudio Heliomar Vicente da Silva

Av. Prof. Moraes Rego, 1235

Centro - Recife

CEP. 50670-901 PE

E-mail: claudio_rec@hotmail.com 